\title{
Screening for peripheral neuropathy and peripheral arterial disease in persons with diabetes mellitus in a Nigerian University Teaching Hospital
}

\author{
Anthonia O. Ogbera ${ }^{1 *}$, Olufunmilayo Adeleye ${ }^{2}$, Babatunde Solagberu ${ }^{3}$ and Alfred Azenabor ${ }^{4}$
}

\begin{abstract}
Background: Identifying the risk factors for diabetes mellitus related foot ulceration would save more limbs from amputation. This report focuses on the determining the burden of peripheral arterial disease and neuropathy in persons with diabetes mellitus (DM).

Methods: This is a descriptive study carried out in the Diabetic Clinic of the Lagos State University Teaching Hospital in patients with DM who had no past/present history of foot ulceration. Biothesiometry was employed and ankle brachial pressure indices were measured to evaluate for neuropathy and peripheral arterial disease (PAD) respectively.

Results: A total of 225 persons living with DM who met inclusion criteria were recruited consecutively over a 3 months period. Age range was 28-87 years with the mean [61.4 (10.8)] and median (63) years respectively. Patients symptomatic for neuropathy and PAD were 37 and $40 \%$ respectively of the study population. An older age of $>60$ years and poor glycaemic control were potential predictors of neuropathy. Neuropathy and PAD occurred commonly in the seventh decade of life.
\end{abstract}

Conclusion: Given the fairly high proportions of neuropathy and PAD in our patients with DM, we recommend that they be routinely examined in persons with DM.

Keywords: Diabetes mellitus, Neuropathy, Peripheral arterial disease

\section{Background}

Peripheral arterial disease, a pointer to the presence of atherosclerosis is oft reported in diabetes mellitus (DM). Potential sequelae of this finding in DM are diverse ranging from cardiovascular morbidity, the development of foot ulceration, increased risk for amputations and depending on severity, may result in death from any of the aforestated complications of DM. Neuropathy is a commonly documented complication of DM which may be asymptomatic but may lead to reduced quality of life in people who have painful neuropathy. Neuropathy is a

\footnotetext{
*Correspondence: oogbera@yahoo.co.uk

${ }^{1}$ Department of Medicine, Lagos State University College Of Medicine,

Ikeja, Lagos, Nigeria

Full list of author information is available at the end of the article
}

well recognised risk factor of foot ulcers in persons with DM.

In order to reduce the burden of cardiovascular and foot complications of DM it is imperative to screen persons with DM for these entities. There are a variety of screening techniques which are currently in use and these include the evaluation of vibration perception threshold (VPT) using the biothesiometer and documentation of ABI to detect PAD [1]. In this Report, biothesiometry which has been shown to have good correlation scores with tuning fork, monofilament and ankle reflex was employed for the purposes of quantifying vibratory sense.

Diabetic peripheral neuropathy which is documented to be present in $60 \%$ of diabetic persons confers a great risk of foot ulceration; microvascular disease and 
suboptimal glycemic control are also contributory. The prevalence of neuropathy was $76 \%$ PAD was $6.3 \%$ in patients without a prior history of foot ulceration as earlier reported in 2005 by Ogbera et al. [2]. The results of the Diabcare Report published in 2008, showed that peripheral neuropathy was documented in $59.2 \%$ of persons with DM in Nigeria [3]. When compared to the $33 \%$ by Kinnear in 1963 [4] and $48 \%$ by Osuntokun et al. in 1971 [5], it is evident that peripheral neuropathy is on the increase in Nigeria.

People living with DM are at high risk for PAD which unfortunately is often associated with poor prognosis of foot ulceration. The determination of PAD using clinical symptoms is unreliable and the presence of neuropathy may be contributory to this scenario. Given the inconsistencies associated with the symptoms of PAD, the measurement of ankle-brachial pressure index (ABI) is an objective relatively simple, non-invasive and inexpensive technique employed in the evaluation of PAD. ABI test is widely used in the hospital setting not only to screen asymptomatic patients but also to diagnose patients with clinical symptom of PAD. In a Nigerian report on middle and elderly patients with DM, the prevalence rate of PAD was found to be $53 \%$ [6]. Reports on PAD and neuropathy from Nigeria have hardly assessed these entities objectively. Currently, health care providers in Nigeria are better equipped to detect neuropathy and PAD in a more objective manner than in the past two decades.

This study was done to document the burden of PAD and neuropathy in persons with DM.

\section{Methods}

This is a descriptive Study carried out at the Diabetes Clinic of the Lagos State University Teaching Hospital (LASUTH), Ikeja, Nigeria. This is a 750 bed hospital upgraded in 2001 from a General Hospital to a teaching hospital. It is located in the capital of Lagos State with highly subsidized health care costs as a result of governmental policy.

Consenting patients were recruited consecutively over a 3-month period. All persons living with DM aged more than 20 years and who had no past histories of foot ulceration, were recruited into the study. Ethical approval was obtained from the Lagos State University Teaching Hospital.

Demography validated interviewer administered questionnaires were used to obtain histories pertaining to clinical characteristics of DM status and complications of neuropathy and PAD, smoking, alcohol and co-morbidities such as hypertension. Long duration of DM means $>10$ years and older age referred to $>60$ years.

The anthropometric indices measured included waist circumference, height and body weight, and the body mass index (BMI) in weight $/ \mathrm{height}^{2}\left(\mathrm{~kg} / \mathrm{m}^{2}\right)$. Waist circumference was determined by applying a tape measure to the midpoint between the inferior margin of the last rib and the crest of the ilium. The blood pressure was measured both in supine and upright positions.

A biothesiometer was used to determine semi quantitatively vibration perception thresholds in a standardized manner by a single observer. The biothesiometer probe, which vibrates at an amplitude proportional to the square of the applied voltage, was applied perpendicularly to the test site with a constant and firm pressure. Subjects were initially familiarized with the sensation by holding the then measured at the distal plantar surface of great toe of both the legs. The voltage was slowly increased at the rate of $1 \mathrm{mV} / \mathrm{sec}$ and the VPT value was defined as the voltage level when the subject indicated that he or she first felt the vibration sense.

DM Neuropathy referred to a vibration perception threshold values of more than $15 \mathrm{mV}$ with or without the presence of neuropathic symptoms [7].

A hand held Doppler equipment with a frequency of $12 \mathrm{MHz}$ was used to document the ABI. The ABI was performed by measuring the systolic blood pressure from both brachial arteries and from both the dorsalis pedis and posterior tibial arteries after the patient has been at rest in the supine position for $10 \mathrm{~min}$. We used a standard blood pressure cuff at the ankle. We began recording the pressures with the right arm, then the right leg, then the left leg, and finally the left arm.

The higher systolic blood pressure value was used as the numerator of the ABI in each limb. (An ABI of $>1.30$ denoted incompressibility of the vessels and persons with such readings were excluded from the analyses). The diagnostic criteria for PAD based on the ABI were interpreted as follows:

Normal if 0.91-1.30, Mild obstruction if $0.70-0.90$, Moderate obstruction if $0.40-0.69$, Severe obstruction if $<0.40$, Poorly compressible if $>1.30$ [8].

HbA1c was assayed using a fully automated Boronate Affinity assay for the determination of the percentage of hemoglobin A1C (HbA1c \%) in whole blood. Poor glycaemic control consisted of glycosylated hemoglobin (Hba1c) levels of $\geq 7 \%$ [9].

Hypertension was said to be present in persons known to have a history of elevated blood.

Fasting blood samples were taken for the determination of four parameters of the lipid profile viz total cholesterol (TCHOL), high density lipoprotein cholesterol (HDL-C), and triglyceride (TG). Total cholesterol assay was done using a modified method of Liebermann-Burchard, HDLcholesterol by precipitation method and TG was estimated using a kit employing enzymatic hydrolysis of TG 
with lipases [10]. LDL-C was calculated using the Friedwald's formula [10] LDL $=(\mathrm{TCHOL}-\mathrm{HDL}-\mathrm{C})-\mathrm{TG} / 5$ when the values of TG were less than $400 \mathrm{mg} \%$. Abnormal lipid profile consisted of the following abnormalities either singly or in combination; triglyceride (TG) levels $\geq 150 \mathrm{mg} \%$, high density lipoprotein cholesterol (HDLC) (for men $\leq 40 \mathrm{mg} \%$ and women $\leq 50 \mathrm{mg} \%$ ), low density lipoprotein cholesterol (LDL-C) $\geq 100 \mathrm{mg} \%$ [10].

Statistical analyses were performed with SPSS version 15. A multiple regression analysis with $\mathrm{PAD}$ as the dependent variable in conjunction with multiple independent variables was used to evaluate for possible predictors of PAD. Independent sample Student's t test was used to compare quantitative data. $\chi^{2}$ was used to test for differences in proportions. A p value of $\leq 0.05$ was deemed significant.

\section{Results and discussion Results}

A total of 225 persons living with DM met the inclusion criteria. The age range was $28-87$ years with the mean and median ages of the as 61.4 (10.8) and 63 years respectively. There were 163 (68\%) females giving a M: F ratio of 1:2.6. The mean age of the males was greater than that of females and the difference was statistically significant (63.6 vs $60.4, \mathrm{p}=0.03$ ).

Other clinical parameters are shown in Table 1.

\section{Risk factors for DMFS}

Neuropathy: Neuropathy was detected in 120 (56 \%) of the study population. The proportions of females and males with neuropathy were comparable (M, 57 vs $56 \% \mathrm{~F}$, $\mathrm{p}=0.9$ ). Persons with neuropathy were older than those without neuropathy and this difference was statistically significant (63.9 (9) vs 58.2 (11) years, $\mathrm{p}=0.0001$ ). Positive symptoms of neuropathy ranging from burning nocturnal pain, pin and needle sensation were noted in 68 patients and negative symptoms of numbness was documented in 16 patients. Poor long term glycaemic control and being elderly as shown in Table 2 were some factors that were found to be predictive for the occurrence of peripheral neuropathy. More than half-47 (52\%) of the people with DM who had neuropathy also had PAD. A comparison of some clinical parameters between patients with neuropathy and those without neuropathy showed that these indices were comparable in both groups; BMI (27.5 vs $27.8, \mathrm{p}=0.6$ ), waist circumference indices (93.1 vs $92.1, \mathrm{p}=0.6)$, glycosylated haemoglobin (7.7 vs 7.7 $\mathrm{p}=0.9)$ and duration of DM (9.7 vs 8.6, $\mathrm{p}=0.8)$.

\section{Peripheral arterial disease}

The total number of persons with PAD was 90 (40\%). The proportions of females and males PAD were comparable
Table 1 Clinical characteristics of the DM patients evaluated for risk factors of foot ulceration

\begin{tabular}{lcr}
\hline Parameter & Mean (SD) & \multicolumn{1}{c}{ Range } \\
\hline Age (years) & $61.4(10.8)$ & $28-87$ \\
Duration of DM (years) & $9.2(7.6)$ & $8-44$ \\
Body mass index $\left(\mathrm{kg} / \mathrm{m}^{2}\right)$ & $27.6(4.6)$ & $17.5-42.5$ \\
Waist circumference $(\mathrm{cm})$ & $92.8(12)$ & $31-120$ \\
Haemoglobin $(\mathrm{HbA1c})(\%)$ & $7.7(2.1)$ & $5-14$ \\
\hline
\end{tabular}

Table 2 Predictors of peripheral neuropathy in patients with diabetes mellitus

\begin{tabular}{lccl}
\hline Variables & OR & $\begin{array}{l}\text { 95 \% confidence } \\
\text { interval }\end{array}$ & p value \\
\hline Age $>60$ years & 2.6 & $1.4-4.8$ & 0.02 \\
Elevated HbA1C & 2.0 & $1.1-3.80$ & 0.002 \\
Low HDL-C & 2.1 & $0.4-8.3$ & 0.3 \\
Male sex & 1.54 & $0.78-3$ & 0.2 \\
Elevated LDL-C & 1.49 & $0.6-3.3$ & 0.3 \\
Duration of DM $>$ 10 years & 1.29 & $0.7-2.6$ & 0.4 \\
Elevated TCHOL & 1.1 & $0.4-2.5$ & 0.8 \\
Elevated TG & 0.87 & $0.4-1.8$ & 0.7 \\
Overweight/obese & 0.86 & $0.45-1.66$ & 0.8 \\
History of hypertension & 0.72 & $0.36-0.72$ & 0.3 \\
PAD & 0.73 & $0.42-1.3$ & 0.3 \\
\hline
\end{tabular}

(M, 43 vs $39 \%, \mathrm{p}=0.9)$. The mean age of persons with PAD and those without PAD was comparable. The results of comparisons made for some clinical and biochemical parameters between persons with PAD and persons without PAD is shown in Table 3.

DM associated neuropathy and peripheral arterial disease were prominent in the seventh decade of life. These results are shown in Fig. 1.

\section{Dyslipidaemia}

The proportions of the Study population with elevated total cholesterol, LDL-C, TG and low HDL levels were 99

Table 3 Comparison of clinical parameters between subjects with PAD and those without PAD

\begin{tabular}{lccc}
\hline Parameter & $\begin{array}{l}\text { Patients with no } \\
\text { PAD }\end{array}$ & $\begin{array}{l}\text { Patients } \\
\text { with PAD }\end{array}$ & p \\
\hline Age (years) & $61.2(10.9)$ & $61.5(10.6)$ & 0.8 \\
Body mass Index $\left(\mathrm{kg} / \mathrm{m}^{2}\right)$ & $27.8(4.6)$ & $27.5(4.6)$ & 0.8 \\
HbA1c $(\%)$ & $7.9(2.2)$ & $7.5(1.8)$ & 0.1 \\
Duration of DM (years) & $9.5(7.7)$ & $8.9(7.6)$ & 0.5 \\
Waist circumference $(\mathrm{cm})$ & $93(12.7)$ & $92.5(11.2)$ & 0.3 \\
\hline
\end{tabular}




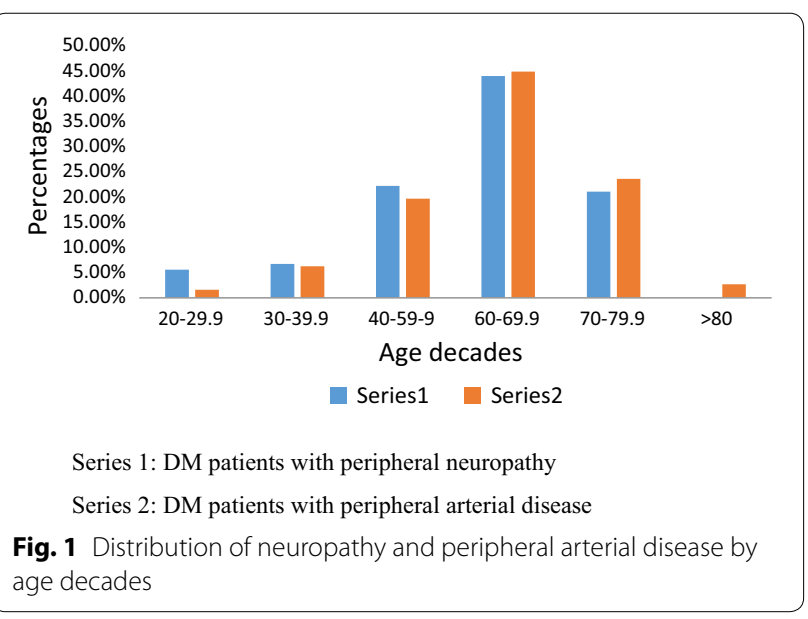

(44\%), 44 (20\%), $129(57 \%)$ and $66(29 \%)$ respectively. A comparison of the distribution of abnormal lipid parameters between DM patients with PAD and DM patients with neuropathy is shown in Fig. 2.

\section{Discussion}

There is a growing awareness amongst healthcare professionals on the importance of early detection of risk factors for diabetes mellitus foot ulceration especially because this complication of DM has been associated with a high disease morbidity and mortality in resource poor countries.

In this report, neuropathy was a commonly documented entity and painful neuropathy its prominent symptom was noted in about half of the patients studied. Impaired vibration sense is an early sign of neuropathy, hence its assessment is an important element of the neurological examination of the patient with diabetes [11]. We screened for neuropathy by means of biothesiometer, a recognised method of testing for vibration sensation. In

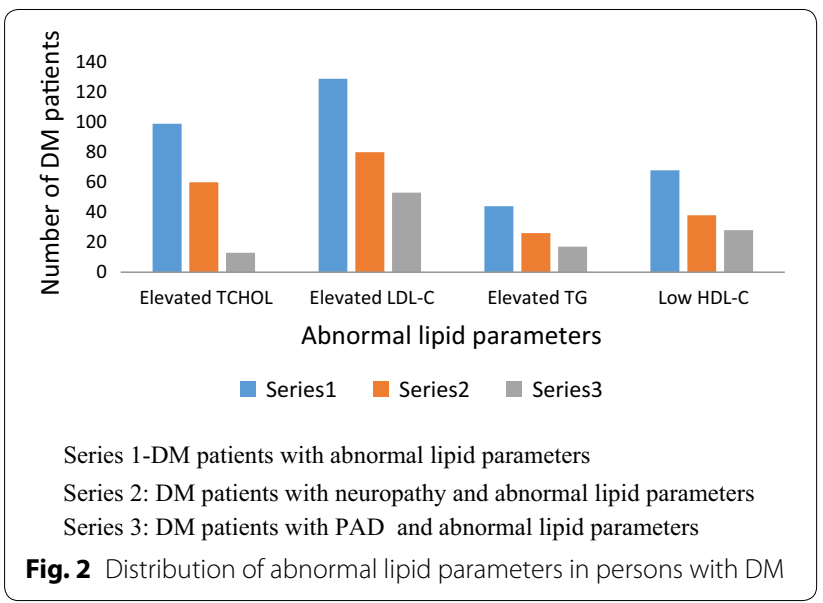

a Study that compared the efficacy of the use of a biothesiometer with that of the tuning fork the biothesiometer was found not only to have comparable efficacy to the tuning fork but was more useful in large outpatient clinics [11]. In a Nigerian Study that reported the presence of neuropathy in persons with DM, the results showed that Bio-thesiometry detected neuropathy in $47.8 \%$ of those with duration of DM $<5$ years and $100.0 \%$ in those with duration of DM $>15$ years [12]. In our Report, neuropathy was diagnosed more in older persons with an odds ratio (OR) of 2.6 for above 60 years (nearly three higher risk). Although an association between ageing and the occurrence of neuropathy has been attested to in many pertinent studies [13-15] it is instructive to note that neuropathy may occur in any age group as we have shown in our findings. Other clinical parameters such as duration of DM, glycaemic control, lipid parameters did not differ between persons with DM neuropathy and those without neuropathy.

A possible relation between glycaemic control and DM complications has being pointed out by findings from the UK Prospective Diabetes Study (UKPDS) [16] and not surprisingly our results showed that poor glycaemic control, a readily modifiable risk factor is a possible predictor of DM neuropathy. The prevalence of neuropathy has been reported in a Canadian Study to increase with increasing glucose [17]. The potential role of hyperglycaemia in the pathogenesis of DM neuropathy has been explained by the polyol pathway theory and the glycosylation end product pathway [18]. This is because glucose uptake in peripheral nerves is not dependent on insulin and, high blood glucose levels in diabetes thus leads to high nerve glucose concentrations and this stimulates the polyol pathway [18]. Whilst some studies report duration of DM to be associated with DM related neuropathy, we found no such associations. This scenario may be explained partly by the fact that DMFS presents in $25 \%$ as the initial manifestation of DM in our environment [19].

There is a dearth of Reports on detection on PAD using ABI from Africa. In a recent study from Uganda [20], the author noted that PAD was present in $39 \%$ of persons with DM albeit with a male preponderance. These results are comparable to those of this Study. Our documented prevalence rate of PAD at $40 \%$ is fairly high coming from Africa compared to earlier reported prevalence ranging from 1.7 to $28 \%$ [21]. The results from the Report by Oyelade [6] demonstrates an upward rise of PAD in Nigerians as compared to data obtained some few decades back. Peripheral arterial disease is unfortunately often asymptomatic and remains underdiagnosed in the majority of persons with DM [22]. Given the limitations of relying on the clinical history or physical examination, 
an additional noninvasive test, $\mathrm{ABI}$, is widely adopted for confirmation of a clinical diagnosis of peripheral arterial disease and its quantification. The $\mathrm{ABI}$ is a measure of the blood pressure in the arteries supplying legs relative to central, aortic pressure (approximated by measuring the blood pressure in the arm).

Barring the limitations of occasional high $\mathrm{ABI}$ indices that may be suggestive of incompressibility of the vessels, calculating the ABI for screening purposes is of benefit in detecting PAD even in the absence of foot ulcers. However it is imperative to note that the handheld Dopplers equipment does not give waveform pattern as and such, may fail to detect the PAD when Monckebergs sclerosis is present. We excluded persons with high ABI because of the potential of misleadingly high figures in detected PAD.. Hitherto, apart for research purposes, screening for PAD is not carried out routinely for persons living with DM in the hospital setting in hospitals in Lagos. Of interest also are our findings of comparable clinical and biochemical parameters between patients with PAD and patients without PAD. In this Report, PAD, was diagnosed albeit in a few persons even in persons who were aged less than 40 years. Hypertension and dyslipidaemia, though of fairly high prevalence rate, their role in the possible development of PAD and neuropathy could not be ascertained in this report.

\section{Limitations of the study}

We did not document waveform patterns whilst examining for PAD.

\section{Conclusion}

The burden of Peripheral neuropathy and peripheral arterial disease is high and may go undetected if not screened for. We recommend that PAD and neuropathy be screened for in diabetic clinics.

\begin{abstract}
Abbreviations
PAD: peripheral arterial disease; $\mathrm{ABl}$ : ankle brachial pressure index; $\mathrm{HbA1c}$ : glycosylated haemoglobin; TCHOL: total cholesterol; HDL-C: high density lipoprotein cholesterol; TG: triglyceride; LDL-C: low density lipoprotein cholesterol; BMI: body mass index; DMFS: diabetes mellitus foot syndrome; DM: diabetes mellitus.
\end{abstract}

\section{Authors' contributions}

OA conceived of the study, participated in the design, data collation, statistical analysis, and drafting of the manuscript, $\mathrm{AO}$ participated in the design and data collation, SB participated conceived of the study and participated in reviewing and drafting of the manuscript, AA participated in the laboratory analysis and drafting of the manuscript. All authors read and approved the manuscript.

\section{Author details}

${ }^{1}$ Department of Medicine, Lagos State University College Of Medicine, Ikeja, Lagos, Nigeria. ${ }^{2}$ Department of Medicine, Lagos State University Teaching Hospital, Ikeja, Lagos, Nigeria. ${ }^{3}$ Department of Surgery, Lagos State University
College Of Medicine, Ikeja, Lagos, Nigeria. ${ }^{4}$ Department of Medical Laboratory Sciences, University of Lagos, Idi-araba, Lagos, Nigeria.

\section{Acknowledgements}

We wish to acknowledge Mr Samuel Momoh and Wunmi Durotoye who were involved in pooling the patients for the research work.

\section{Compliance with ethical guidelines}

\section{Competing interests}

The authors declare that there is no conflict of interests regarding the publication of this paper.

Received: 14 November 2014 Accepted: 7 September 2015

Published online: 04 October 2015

\section{References}

1. Jayaprakash P, Bhansali A, Bhansali S, Dutta P, Anantharaman R, Shanmugasundar $\mathrm{G}$, et al. Validation of bedside methods in evaluation of diabetic peripheral neuropathy. Indian J Med Res. 2011;133(6):645-9.

2. Ogbera AO, Adedokun A, Fasanmade OA, Ohwovoriole AE, Ajani M. The foot at risk in Nigerians with diabetes mellitus: the Nigerian scenario. Int J Endocrinol Metabol. 2005;4:165-73.

3. Chinenye S, Uloko AE, Ogbera AO, Ofoegbu EN, Fasanmade OA, Fasanmade AA, Ogbu OO. Profile of Nigerians with diabetes mellitus-Diabcare Nigeria study group (2008): results of a multicenter study. Indian J Endocr Metab. 2012;16:558-64.

4. Kinnear TWG. The pattern of diabetes mellitus in a Nigerian teaching hospital. East Afr Med J. 1963;40:288-94.

5. Osuntokun BO, Akinkugbe FM, Francis TI, Reddy S, Taylor GOL. Diabetes mellitus in Nigerians: a study of 832 patients. West Afr Med J. 1971;20:295-312.

6. Oyelade BO, OlaOlorun AD, Odeigah LO, Amole IO, Adediran OS. The prevalence of peripheral arterial disease in diabetic subjects in southwest Nigeria. Afr J Prm Health Care Fam Med. 2012;4(1):354-6.

7. Saha D, Saha K, Dasgupta PK. Vibration sense impairment in diabetes mellitus. Indian J Physiol Pharmacol. 2011;55:381-3.

8. American Diabetes Association. Peripheral arterial disease in people with diabetes. Diabetes Care. 2006;26(12):3333-41.

9. American Diabetes Association. Standards of medical care in diabetes-2015. Diabetes Care. 2015;38(1):S1-94.

10. Ogbera AO, Fasanmade O, Chinenye S, et al. Characterization of lipid parameters in diabetes mellitus-a Nigerian report. Int Archiv Med. 2009;2:19. doi:10.1186/1755-7682-2-19.

11. Tochman-Gawda A, Paprzycki P, Dziemidok P. A tuning fork or a biothesiometer: which one to choose in the outpatient diabetes care? Diabetologia Doświadczalna i Kliniczna. 2007;7:13-9.

12. Oguejiofor OC, Odenigbo CU, Oguejiofor CB. Evaluation of the effect of duration of diabetes mellitus on peripheral neuropathy using the United Kingdom screening test scoring system, bio-thesiometry and aesthesiometry. Niger J Clin Pract. 2010;13(3):240-7.

13. Tesfaye S, Stevens LK, Stephenson JM, Fuller JH, Plater M, lonescu-Tirgoviste C, Nuber A, Pozza G, Ward JD. Prevalence of diabetic peripheral neuropathy and its relation to glycemic control and potential risk factors. The Euro Diab IDDM complications study. Diabetologia. 1996:39(11):1377-84.

14. Booya F, Bandarian F, Larijani B, Pajouhi M, Nooraei M, Lotfi J. Potential risk factors for diabetic neuropathy: a case control study. BMC Neurol. 2005;5:24. doi:10.1186/1471-2377-5-24.

15. Ashok S, Ramu M, Deepa R, Mohan V. Prevalence of neuropathy in type 2 diabetic patients attending a diabetes centre in South India. J Assoc Physicians India. 2002;50:546-50.

16. American Diabetes Association. Implications of the United Kingdom prospective diabetes study. Diabetes Care. 2002;25(1):s28-32.

17. Bruce GS, Young K. Prevalence and risk factors for neuropathy in a Canadian first nation community. Diabetes Care. 2008;31:1837-41.

18. Kelkar P. Diabetic neuropathy. Semin Neurol. 2005;25(2):168-73.

19. Ogbera O, Chinenye S, Onyekwere C, Fasanmade A. Prognostic indices of DM mortality. Ethn Dis. 2007;17(4):721-5. 
20. Mwebaze RM, Kibirige D. Peripheral arterial disease among adult diabetic patients attending a large outpatient diabetic clinic at a National Referral Hospital in Uganda: a descriptive cross sectional study. PLoS One. 2014:9(8):e105211.

21. Kengne PA, Amoah AGB, Mbanya JC. Cardiovascular complications of diabetes mellitus in Sub-Saharan Africa. Circulation. 2005;112(23):3592-601.
22. Al-Qaisi M, Nott DM, King DH, Kaddoura S. Ankle brachial pressure index (ABPI): an update for practitioners. Vasc Health Risk Manag. 2009;5:833-41.

\section{Submit your next manuscript to BioMed Central} and take full advantage of:

- Convenient online submission

- Thorough peer review

- No space constraints or color figure charges

- Immediate publication on acceptance

- Inclusion in PubMed, CAS, Scopus and Google Scholar

- Research which is freely available for redistribution

Submit your manuscript at

www.biomedcentral.com/submit

() Biomed Central 